\title{
Exploration on the Education Mode of Effectively Strengthening Security Awareness and Ability of Female College Students
}

\author{
Qinlan Lin ${ }^{1, a}$, Kai Wang ${ }^{2, b^{*}}$, Ling Gao ${ }^{1, c}$ \\ ${ }^{1}$ College of Nursing, Beihua University, Jilin, China \\ ${ }^{2}$ College of Electrical \& Information Engineering, Beihua University, Jilin, China \\ a1010340876@qq.com, b178971787@qq.com, 'bhgaoling@sina.cn
}

Keywords: female college students; safety awareness; education

\begin{abstract}
In 2014, the frequent occurrence of female students in China: the disappearance, the lack of safety education has become an indisputable fact. To strengthen the safety education of female college students, has practical significance to the University and society, has a practical significance for female college students themselves. The author analyzes the main problems of female college students' self safety awareness and emergency response capabilities through the questionnaire survey method, and puts forward the corresponding effective way of education.
\end{abstract}

\section{Introduction}

In higher education, vigorously promoting quality education today, female college students as a special social group, self safety consciousness has not received enough attention, the education system is not perfect. At present, female college students'injury accidents have been reported, particularly in freshmen strengthening the self-education of safety consciousness of female college students is particularly important.

\section{A Survey of the Status Quo is About Female College Students' Safety Awareness and Prevention Ability.}

Investigation Object and Method of the Survey

Investigation object and method of the survey by BeiHua University, Northeast DianLi University, Jilin chemical university students as the research object, selects the conference room, classroom, dormitory, library for investigation, using the questionnaire and interview survey of two survey method. The questionnaire mainly by means of random sampling in each of 200 university students, the first grade 200 the second grade students and 200 graduate students to carry out investigation, a total of 1800 questionnaires (the total number of the students in the school 12\%), 1662 valid questionnaires (585 copies in the first grade, the second grade 573 graduation, grade 504), the questionnaire was $92.3 \%$, the sample fully reflects the representative and extensive investigation; interviews mainly to organize seminars, to carry out the theme class meeting to discuss the campus, random interviews, direct dialogue with the students exchange, listen to the opinions and suggestions of the students, in-depth understanding of ideological trend and knowledge of the needs of the students, to fully grasp the situation of safety awareness and prevention ability of the students, fully prepared for further analysis and research.

\section{The Content and Topic of Survey}

In this survey, according to the characteristics of female college students is to study, life, work, communication and other activities as well as the psychological characteristics of young women in the selection and determination of content of investigation. The topic design questionnaire focuses on female college students' property safety (anti-theft, anti fraud, anti robbery), female college students' personal safety (anti collisions, anti robbery, anti sexual assault), female students' interpersonal security (anti harassment, anti sexual harassment), female college students burst disaster safety(fire, earthquake), female college students network security (online safety, network information security, network security, shopping) (female 
college students' employment security work safety, safety practice, employment security, health and safety) and female students (mental health, physical health, disease prevention and control) and eight female college students' activities such as security, with 20total question 50 the capacity of the investigation of female college students, personal property security awareness level and prevention skills; subject design interview survey focuses on the four aspects of female college students are most concerned about the security content, security knowledge, female college students the most popular form of safety education of female college students and the lack of the female college students unwilling to accept the safety management mode.

\section{According to the Survey Results, Analyze the Main Problems of Female College Students' Safety Consciousness}

Through the statistical analysis of 1662 questionnaires, we draw the following findings from the feedback information from students, namely the female college students' safety awareness and prevention of serious lack of ability. Firstly, they are lack of necessary safety awareness. Many female college students' social experience, work experience, has not established a good crisis consciousness and concept of human rights. Second, the lack of ability to live independently in many female college students are used to good safety behavior is poor, not with others, effective communication, for example, their own items placed at random, easily trust strangers when they go out, don't take good care of their belongings, alone go out too late, do not develop the habit of good safety behavior. Thirdly, there is lack of security knowledge system. Female college students are lack of basic knowledge of legal rights. They do not know how to use legal weapons to protect their legitimate rights and interests, will not take effective negotiation means to deal with the problem of flood, fire, earthquake, little sudden disasters such as related prevention knowledge, and the lack of the necessary knowledge, self defense. Fourthly, there is lack of effective crisis management skills. In the face of a lot of sexual harassment of female college students in social communication, do not know how to observe, not dare to blame, not to prevent, which would pose a serious threat to its security.

Through the summary of discussion record data of 50 students interview and 50 branch of the group, we know that the security content of the current concern of female college students is the female college students' personal safety and safety of female college students' employment; security knowledge is most lacking in female college students in disaster prevention and emergency safety of female students' interpersonal safety; the most popular safety education is the "practical exercise of personal simulation and on-site guidance" by conventional teaching learning system specifically for practical security knowledge of female college students; most unwilling to accept the safety management regulations are blunt rigid access prohibition and conventional dormitory safety inspection.

\section{To Enhance the Education Strategy of the Female College Students' Safety Consciousness}

Analysis of the concept, characteristics and the current situation of safety awareness of female college students, the purpose of which is to strengthen and cultivate the self security of female college students and coping ability, and to do this, must address the major problems of contemporary female college students self security awareness, find the effective way of education.

In the School Security Department as the Leading, Fully Mobilize the Power of Other Relevant Departments, The Formation Of New Situation Catches Condominium

The self safety consciousness of female college students by school education department and the Defense Department of student work is far from enough, must also rely on other departments such as schools, logistics and other departments of the Communist Youth League propaganda, participation and cooperation. The security department can use their own advantages, with the annual "safety month" as an opportunity, vigorously carry out the safety aspects of the activities of the school students, especially female students safety knock once the alarm; secondly, the information in the public places regularly or irregularly to teachers and 
students related to female students informed the security aspects of the case, and for female students illegal security pictures and information to the relevant departments such as the law of teacher. Make them to female students in class more targeted, more close to the lives of female students, can play a better role in publicity and education.

\section{To Establish a Sound Security System, Provide the Basis for Security Awareness Training}

The university should not only formulate college student management manual, but also specifically for female students to formulate a set of safety management regulations, Such as dormitory safety management regulations, class management, campus security management regulations and other regulations. At the same time, some students living close contact and safety to be concentrated, so that the colleges and universities in the culture of female college students self security awareness of rule-based, evidence-based, female students know how to use the rules to regulate their own behavior, to protect their legitimate rights and interests and the safety of life and property.

\section{To Carry Out Safety Education, To Guide The Training in Practice}

To the security concept in the minds of female students into active safety consciousness, must also be in a variety of emergency exercises in exercise. Enhancement of female college students in the activities of organized emergency drills, discipline and confrontational at all, so as to promote female college students' safety awareness, but also can help students in emergency exercises in a profound experience of security on their own and to others, the importance of social. Through a variety of activities can enhance the emergency drills, speculation and judgment of female students on security issues, so as to improve the dynamic response ability of female college students' safety awareness.

\section{Emphasis on Four Facets of Security Education of Girl Students}

One is to do a good job on safety publicity and education when a girl student enters the campus on the first day. . Through publicity and education of the new girls, the students will know the harm of school ideological paralysis. They will understand the importance of their own safety. Two is to do a good job against sex education. By setting up a sense of crisis, strengthen the crisis education and establish crisis early warning measures, improve the discrimination ability of female college students. Three is to grasp the knowledge of sex education. The anti-theft safety education for female college students will make students understand the main goal of theft criminals is cash, mobile phone, computer and other valuables, so as to improve the prevention ability of female college students. Four is to do a good job of psychological health education. The behaviors of female college students in Dutch act mostly with psychological problems. School safety education and mental health education organically can help female college students to overcome the psychological obstacles, and strive to eliminate safety problems in the bud.

\section{To Actively Create Conditions for Female College Students to Participate in the Public Security Management Work}

Public security management work for female college students to participate in school, not only can let them experience the importance of their own safety, and to enhance the safety awareness of female college students is an effective way to improve safety awareness and emergency response capabilities. Firstly, female college students through the management work in public security practice can better understand women safe nature of the work, and not to defend the safety publicity and education departments routinely generate resentment. Secondly, the actual participation of female students, know how to fight against irregularities, so as to improve the self prevention and emergency ability of female college students. Thirdly, female students participating in the process, the violations of the investigation, and correct judgment, recognizing the criminals crime means, in order to improve the consciousness of self awareness, enhance the anti defense and safety emergency response capability. Fourth, the actual participation of female students, understand the importance and necessity of the safety work of public security management, security need to understand all the people involved, it may create a good learning and living environment for ourselves and others, in 
order to ensure their personal safety and property, so as to cultivate goodness into safety consciousness .

\section{Summary}

To improve the safety awareness of female college students is a long-term education, schools need to attach great importance to the relevant departments and make concerted efforts, can receive the good effect, the university departments should coordinate with each other, cooperate closely together, act with united strength, to enhance the female college students' safety awareness and efforts, let the contemporary female college students' healthy and happy growth.

\section{References}

[1] CCTV interpretation of female college students why repeated violations: lack of awareness of [N] China News Online.

[2] Wei Bin on the university campus safety education [J],.2012 Education (4).

[3] Huang Yingbing. [J]. University investigation and Countermeasures of students' safety awareness and skills of safety education, Henan Social Sciences, 2007 (15).

[4] Liu Fangli. The present situation investigation and countermeasure analysis of College Students' safety awareness and prevention [J] skills, higher education research, 2010 (3).

[5] Qin Xianru. Students' safety awareness education model innovation of the [J] front, 2013 (17).

[6] Yang Hongling. Observation of the confusion and Countermeasure of [J]. theoryof female university students' Ideological and political education, 2012 (04). 